\title{
Response of soil water dynamics to precipitation years under different vegetation types on the northern Loess Plateau, China
}

\author{
LIU Bingxia ${ }^{1,2}$, SHAO Ming'an ${ }^{3 *}$ \\ ${ }^{1}$ State Key Laboratory of Soil Erosion and Dryland Farming on the Loess Plateau, Institute of Soil and Water Conservation, \\ Chinese Academy of Sciences and Ministry of Water Resources, Yangling 712100, China; \\ ${ }^{2}$ Key Laboratory of Agricultural Water Resources, Center for Agricultural Resources Research, Institute of Genetics and \\ Developmental Biology, Chinese Academy of Sciences, Shijiazhuang 050021, China; \\ ${ }^{3}$ State Key Laboratory of Soil Erosion and Dryland Farming on the Loess Plateau, Northwest A\&F University, Yangling 712100, \\ China
}

\begin{abstract}
Implementation of the Grain-for-Green project has led to rapid land cover changes and resulted in a significantly increased vegetation cover on the Loess Plateau of China during the past few decades. The main objective of this study was to examine the responses of soil water dynamics under four typical vegetation types against precipitation years. Soil water contents (SWCs) were measured in 0-4.0 m profiles on a hillslope under the four vegetation types of shrub, pasture, natural fallow and crop in a re-vegetated catchment area from April to October in normal (2010), dry (2011), wet (2014) and extremely wet (2013) years. The results indicated that precipitation and vegetation types jointly controlled the soil water temporal dynamics and profile characteristics in the study region. SWCs in $0-4.0 \mathrm{~m}$ profiles of the four vegetation types were ranked from high to low as crop>fallow>pasture>shrub and this pattern displayed a temporal stability over the four years. In the extremely wet year, SWC changes occurred in the 0-2.0 m layer under shrub and pasture while the changes further extended to the depth of 4.0-m deep layers under fallow and crop. In the other three years, SWCs changes mainly occurred in the 0-1.0 m layer and kept relatively stable in the layers deeper than $1.0 \mathrm{~m}$ for all the four vegetation types. The interannual variation in soil depth of SWCs was about $0-2.0 \mathrm{~m}$ for shrub and pasture, about $0-3.4 \mathrm{~m}$ for fallow and about $0-4.0 \mathrm{~m}$ for crop, respectively. The dried soil layers formed at the depths of 1.0, 0.6, 1.6 and $0.7 \mathrm{~m}$ under shrub, and 1.0, 1.0, 2.0 and $0.9 \mathrm{~m}$ under pasture, respectively in 2010, 2011, 2013 and 2014. The infiltrated rainwater mostly stayed in the $0-1.0 \mathrm{~m}$ layer and hardly supplied to soil depth $>1.0 \mathrm{~m}$ in normal, dry and wet years. Even in the extremely wet year of 2013, rainwater recharge depth did not exceed $2.0 \mathrm{~m}$ under shrub and pasture. This implied that soil desiccation was difficult to remove in normal, dry and wet years, and soil desiccation could be removed in 1.0-2.0 m soil layers even in the extremely wet year under shrub and pasture. The results indicated that the natural fallow was the best vegetation type for achieving sustainable utilization of soil water and preventing soil desiccation.
\end{abstract}

Keywords: precipitation pattern; restoration; soil water dynamics; soil desiccation; vegetation type

Citation: LIU Bingxia, SHAO Ming'an. 2016. Response of soil water dynamics to precipitation years under different vegetation types on the northern Loess Plateau, China. Journal of Arid Land, 8(1): 47-59. doi: 10.1007/s40333-015-0088-y

Soil water is a fundamental parameter of hydrological status (Gish et al., 2011; Legates et al., 2011) and a typical primary limiting factor for projects involving environmental rehabilitation, vegetation

\footnotetext{
*Corresponding author: SHAO Ming'an (E-mail: shaoma@igsnrr.ac.cn) Received 2015-03-03; revised 2015-05-07; accepted 2015-05-14

(C) Xinjiang Institute of Ecology and Geography, Chinese Academy of Sciences, Science Press and Springer-Verlag Berlin Heidelberg 2016
} 
structure, and vegetation restoration in arid and semi-arid regions (Ingmar et al., 2003; Messing et al., 2003; Kerkhoff et al., 2004; Huo et al., 2008). The relationship between vegetation type and soil water is a central theme of eco-hydrology, which has been widely discussed and is the subject of many important recent advances ( $\mathrm{Li}, 2011)$. The Loess Plateau of China is one of the regions with the most severe soil erosion in the world, which was mainly caused by cultivation at steep sloping lands and destruction of natural vegetations. The Grain-for-Green project implemented by the Chinese Government aimed to prevent further deterioration of the natural ecosystem and to conserve soil and water, which led to rapid land use/cover changes and significantly increased vegetation cover recoveries during the past few decades. Land use/cover changes are highly dependent on the availability of soil water, which in turn affects soil water dynamics (Wang et al., 2012, 2013; Jia and Shao, 2014), other hydrological processes (Porporato et al., 2002) and water balances (Nosetto et al., 2007; Fu et al., 2012) in arid and semi-arid regions. Limited water resources can hardly sustain the vegetation restoration currently carried out on the northern Loess Plateau. Consequently, soil desiccation has become a serious problem on the Loess Plateau (Wang et al., 2008) due to the combination of excessive depletion of deep soil water resources and longterm insufficient precipitation that prevented soil water replenishment (Shangguan, 2007; Chen et al., 2008a, b). Information about the effects of various vegetation types on soil water dynamics is essential to long-term rational management of water resources and land-use planning, as well as in addressing the problems of unsustainable vegetation restoration.

Soil water, both across the landscapes and within soil profiles, is mainly controlled by the interactive effects of precipitation and vegetation at a macroscopic scale in arid and semi-arid regions. Precipitation is the most important source for soil water replenishment to sustain plant growth on the northern Loess Plateau, as groundwater table in this region is generally deeper than $60 \mathrm{~m}$. Precipitation characteristics or patterns, such as amount, frequency, intensity and seasonal or annual changes, affect the temporal and spatial variability and distributions of soil water (Wilson et al., 2004; Salve et al., 2011; Yao et al., 2013). Li et al. (2013) observed that precipitation amount highly affected variations in surface soil water in shrub-encroached grasslands. Salve et al. (2011) reported that the effect of rainfall on hydrological processes varied among different vegetation types as well as over the growing season. The question then arises: How do the precipitation years influence soil water dynamics and water balances under the different vegetation types? An improved understanding of the response of soil water variability to precipitation years under different vegetation types is crucial for accurately predicting the effects of climatic fluctuations on different ecosystems (D’Odorico et al., 2007).

Numerous studies focused on the responses of soil water to changes in land use and vegetation cover types (Chen et al., 2007, 2010; Mohammad and Adam, 2010; Reszkowska et al., 2011). Some researches carried out in arid areas of China have shown that soil water storages (SWSs) were decreased after afforestation and that deep soil water (deeper than $1.0 \mathrm{~m}$ ) was not recharged by natural precipitation (Farley et al., 2005; Sun et al., 2006). Land use/covers or vegetation covers were considered as the most important factors affecting the hydrological processes and surface wash erosion. Vegetation cover and precipitation years are important factors, which influence the soil water dynamics and soil water hydrology. However, these studies were usually conducted over a short term that did not include different precipitation years. Little attention has been paid to the effects of different precipitation years on soil water dynamics under different vegetation types. It is crucial to the guidance of rational layouts of vegetation restoration projects to understand how the soil water dynamics response to precipitation years under different vegetation types for the vegetation restoration management and the sustainable utilization of soil water. Accordingly, the study examined the temporal-spatial dynamics of soil water under four vegetation types in different precipitation years during the growing seasons of 2010-2014 on the Loess Plateau. The specific objectives of the research were: (1) to evaluate the response of soil water dynamics under the four vegetation types in different precipitation years; and (2) to assess and compare the hydrologic responses of the four vegetation types subjected to different precipitation years. The four vegetation types studied (Caragana (Caragana korshinskii Kom.; shrub), alfalfa (Medicago sativa; pasture), naturally regenerated fallow (natural grass) and soybean or millet (crops)) are the representative 
vegetation commonly found in the Liudaogou catchment. The results of this study would provide a more scientific basis for land use planning and sustainable ecosystem restoration at the hillslope scale and a further understanding of relationships among vegetation type, precipitation years and the soil water budget.

\section{Materials and methods}

\subsection{Study site}

This study was conducted at the Shenmu Soil Erosion and Environment Experimental Station $\left(38^{\circ} 46^{\prime}-38^{\circ} 51^{\prime} \mathrm{N}, 110^{\circ} 21^{\prime}-110^{\circ} 23^{\prime} \mathrm{E}\right.$; $1,094-1,274 \mathrm{~m}$ asl) in the Liudaogou catchment in Shenmu county, Shaanxi province, China. The station is a department of the Institute of Soil and Water Conservation, Chinese Academy of Sciences and Ministry of Water Resources. The catchment was located in the "water-wind erosion "crisscross" region of the Loess Plateau, which undergoes severe soil erosion by wind and water under dry and wet conditions. The annual mean temperature is approximately $8.4^{\circ} \mathrm{C}$ and the mean annual precipitation is $437.4 \mathrm{~mm}$ with about $70 \%$ of which falls between June and September. The natural vegetation was destroyed by human activities in the past and, more recently, widespread vegetation restoration has been attempted in order to improve the ecological environment. The restoration involved either planting perennial plants, including purple alfalfa, Caragana and desert willow (Salix psammophila), or setting aside fallow land formerly used for crop production to enable the natural regeneration of native vegetation. Caragana and desert willow are native species on the Loess Plateau, although not necessary for the study area, while alfalfa is a nonindigenous species.

\subsection{Data and sources}

Four adjacent plots $(61 \mathrm{~m} \times 5 \mathrm{~m})$ were established in 2004 on slopes with a uniform gradient $(12$ $14^{\circ}$ ) under four different vegetation types such that the long edge of the plots was along the downslope direction (Fig. 1). Eleven 4-m neutron-probe access tubes were installed at 5.0-m intervals

\begin{tabular}{|c|c|c|c|c|c|c|c|c|c|c|c|}
\hline & $0^{\mathrm{a} 1}$ & $0^{a 2}$ & $0^{a 3}$ & $\bigcirc^{a 4}$ & $0^{a 5}$ & $0^{a 6}$ & $0^{a 7}$ & $0^{a 8}$ & $\mathrm{O}^{\mathrm{a} 9}$ & $0^{\mathrm{a} 10}$ & $0^{a 11}$ \\
\hline & $0^{b 1}$ & $0^{b 2}$ & $0^{b 3}$ & $0^{b 4}$ & $0^{b 5}$ & $0^{b 6}$ & $0^{b 7}$ & $0^{b 8}$ & $0^{\mathrm{b} 9}$ & $0^{b 10}$ & $0^{b 11}$ \\
\hline & $0^{\mathrm{c} 1}$ & $0^{c 2}$ & $0^{c 3}$ & $0^{\mathrm{c} 4}$ & $0^{c 5}$ & $0^{c 6}$ & $0^{c 7}$ & $0^{c 8}$ & $0^{\mathrm{c} 9}$ & $\bigcirc^{\mathrm{c} 10}$ & $0^{\mathrm{c} 11}$ \\
\hline & $0^{\mathrm{d} 1}$ & $0^{\mathrm{d} 2}$ & $\mathrm{O}^{\mathrm{d} 3}$ & $O^{d 4}$ & $\mathrm{O}^{\mathrm{d} 5}$ & $0^{\mathrm{d} 6}$ & $0^{d 7}$ & $0^{\mathrm{d} 8}$ & $\mathrm{O}^{\mathrm{d} 9}$ & $0^{\mathrm{d} 10}$ & $0^{\mathrm{d} 11}$ \\
\hline
\end{tabular}

Fig. 1 The four vegetation types of shrub, pasture, fallow, and crop with the positions of neutron probe access tubes in each plot (from the top to the bottom marked as $1,2, \ldots, 11$ )

along the center line of each plot. The four vegetation types consisted of three typical vegetation restoration types, Caragana, alfalfa, naturally regenerated grass and soybean or millet which were cultivated in rotation. The Caragana were planted at a planting spacing of $70 \mathrm{~cm} \times 70 \mathrm{~cm}$, and alfalfa were planted with a row spacing of $50 \mathrm{~cm}$ in 2004 . The Caragana was left to grow naturally without human disturbance while the alfalfa was harvested twice every year in late July and late October (cut near the soil surface). The fallow treatment developed naturally without human disturbance as well after the arable land was abandoned in 2004 and the predominant species in 2013 in the land were Astragalus sinicus, Artemisia capillaries, Leymus secalinus, Poa sphondylodes and Stipa bungeana. Under the crop treatment, the plot remained without vegetation cover until sowing and soybeans were sown in May and then harvested in October. The crop plot was weeded twice during 
the growing season.

The soil in the plots was aeolian loess that was classified as a Camisole according to the FAO/UNESCO soil classification system, which was composed of $45.4 \%-50.9 \%$ sand, $30.1 \%$ $44.5 \%$ silt and $11.2 \%-14.3 \%$ clay in 2004 (Zeng et al., 2011). The background levels of soil organic matter, total nitrogen, bulk density, and hydraulic conductivity of the top $0-20 \mathrm{~cm}$ soil layer on the hillslope were $1.62 \mathrm{~g} / \mathrm{kg}, 0.18 \mathrm{~g} / \mathrm{kg}, 1.50 \mathrm{~g} / \mathrm{cm}^{3}$, and $0.94 \mathrm{~mm} / \mathrm{min}$, respectively (Fu et al., 2012). Relevant soil physical properties of the four experimental plots in 2013 are given in Table 1 . There were no significant differences in particle size distribution in the top $20-\mathrm{cm}$ soil layers among the vegetation types.

Table 1 Soil physical properties of 0-20 cm depth under the four vegetation types in 2013

\begin{tabular}{|c|c|c|c|c|c|c|c|c|}
\hline \multirow{2}{*}{ Plot } & \multirow{2}{*}{$\begin{array}{c}\text { Depth } \\
(\mathrm{cm})\end{array}$} & \multirow{2}{*}{$\begin{array}{l}\text { Clay } \\
(\%)\end{array}$} & \multirow{2}{*}{$\begin{array}{l}\text { Silt } \\
(\%)\end{array}$} & \multirow{2}{*}{$\begin{array}{c}\text { Sand } \\
(\%)\end{array}$} & \multirow{2}{*}{$\begin{array}{l}\text { Bulk density } \\
\left(\mathrm{g} / \mathrm{cm}^{3}\right)\end{array}$} & \multirow{2}{*}{$\begin{array}{c}\mathrm{Ks} \\
(\mathrm{mm} / \mathrm{min})\end{array}$} & \multicolumn{2}{|c|}{ Vegetation cover } \\
\hline & & & & & & & Percentage (\%) & Type \\
\hline \multirow{2}{*}{ Shrub } & 10 & 9.6 & 36.6 & 53.8 & 1.34 & 0.447 & \multirow{2}{*}{70} & \multirow{2}{*}{ Caragana } \\
\hline & 20 & 9.9 & 37.4 & 52.6 & 1.42 & 0.294 & & \\
\hline \multirow{2}{*}{ Pasture } & 10 & 9.8 & 38.6 & 51.5 & 1.40 & 0.412 & \multirow{2}{*}{45} & \multirow{2}{*}{ Alfalfa } \\
\hline & 20 & 15.2 & 41.3 & 43.5 & 1.45 & 0.365 & & \\
\hline \multirow{2}{*}{ Fallow } & 10 & 10.2 & 41.8 & 48.0 & 1.41 & 0.542 & \multirow{2}{*}{55} & \multirow{2}{*}{ Natural grass } \\
\hline & 20 & 8.5 & 41.5 & 50.0 & 1.43 & 0.474 & & \\
\hline \multirow{2}{*}{ Crop } & 10 & 11.9 & 42.5 & 45.7 & 1.35 & 0.386 & \multirow{2}{*}{30} & \multirow{2}{*}{ Soybean/millet } \\
\hline & 20 & 11.7 & 45.9 & 42.4 & 1.43 & 0.288 & & \\
\hline
\end{tabular}

Note: Ks represents the saturated hydraulic conductivity. The coverage was the lagegest vaule for each vegetation type during the growing season in each year.

Soil water content (SWC) was measured fortnightly during the growing seasons (April to October) of 2010-2014 using a calibrated neutron probe (CNC 503DR Hydroprobe; Beijing Super Power Company, Beijing, China). The volumetric SWCs in the $0-4.0 \mathrm{~m}$ profiles were measured for $0.1 \mathrm{~m}$ intervals at soil depth of $0-1.0 \mathrm{~m}$ and for $0.2 \mathrm{~m}$ intervals at soil depth deeper than $1.0 \mathrm{~m}$. The volumetric SWCs $(\theta, \%)$ at each depth were calculated with slowing neutron counting rates (CR), using the following linear calibration curves:

$$
\theta=57.36 \times C R+3.64 \quad\left(R^{2}=0.797 ; 0-1.0 \mathrm{~m}\right), \quad(1) \quad \theta=66.28 \times C R-1.15 \quad\left(R^{2}=0.925 ;>1.0 \mathrm{~m}\right) .
$$

Since SWCs were measured for 11 locations and for different soil layers, the mean volumetric SWC of a given vegetation type and layer at a particular time was calculated using the following equation:

$$
\overline{\theta_{i}}=\frac{1}{N} \sum_{j=1}^{N} \theta_{i j},
$$

where $\overline{\theta_{i}}$ is the mean SWC $\left(\mathrm{cm}^{3} / \mathrm{cm}^{3}\right)$ of the ith layer of the given vegetation type; $\theta_{i j}$ is the SWC $\left(\mathrm{cm}^{3} / \mathrm{cm}^{3}\right)$ measured at $\mathrm{j}^{\text {th }}$ location of the plot; and $N$ is the total number of probe locations in each plot $(N=11)$.

The soil water storage (SWS, $\mathrm{mm}$ ) in each vegetation type was calculated using the following equation:

$$
\mathrm{SWS}=1000 \sum_{i=1}^{N_{y}} \bar{\theta}_{i} \Delta z,
$$

where $N_{y}$ is the total number of soil layers $(i)$ at each probe location; $\Delta z$ is the sampling soil depth increment $(\mathrm{m})$, i.e. $\Delta \mathrm{z}=0.1 \mathrm{~m}$ for the layers between 0 and $1.0 \mathrm{~m} ; 0.2 \mathrm{~m}$ for depths between 1.0 and $4.0 \mathrm{~m}$. The constant, 1,000, converts meter of depth to millimeter. Since the SWC was measured to depth of $4.0 \mathrm{~m}$, SWS was thus calculated for the $0-4.0 \mathrm{~m}$ soil profile.

All precipitation data during the study period (2010-2014) was obtained from an automatic metorological station at the study site. The annual precipitation, precipitation during the growing season and five-year mean precipitation from 1971 to 2014 in the study area presented in Fig. 2.

The distribution of annual and inter-annual precipitation is uneven in the study area. The precipitation between April and October accounted for about $90 \%$ of the annual precipitation according to data collected from 1971 to 2014 at the Shenmu Station (Fig. 2). Therefore, this study 
focused on the precipitation occurring between April and October (growing season) from 2010 to 2013 (Fig. 3). The precipitation years are always divided into three types as follow, using the domestic common division standard (Tao et al., 2000):

$$
P_{a}>\overline{\mathrm{P}}+0.33 \delta, \quad P_{b}>\overline{\mathrm{P}}-0.33 \delta \text {, }
$$

where, $P_{a}$ is the amount of precipitation during growing season in wet year $(\mathrm{mm}) ; P_{b}$ is the amount of precipitation in dry year $(\mathrm{mm}) ; \overline{\mathrm{P}}$ is the mean precipitation for many years during growing season $(\mathrm{mm}) ; \delta$ is the mean square error.

Wang et al. (1996) divided the annual precipitation into five levels as showed in Table 2, according the ratio of $\Delta \mathrm{P}$ to. $\Delta \mathrm{P}$ is the difference of precipitation amount with the mean precipitation $(\overline{\mathrm{P}})$ during growing season.

Table 2 The precipitation years divided

\begin{tabular}{cccccc}
\hline & Extremely dry & Dry & Normal & Wet & Extremely wet \\
\hline$\Delta \mathrm{P} / \overline{\mathrm{P}}$ & $<-40 \%$ & $-40 \%--15 \%$ & $-15 \%-15 \%$ & $15 \%-40 \%$ & $>40 \%$ \\
\hline
\end{tabular}

Note: $\Delta \mathrm{P}=\mathrm{P}_{\mathrm{i}}-\overline{\mathrm{P}}$ (Pi is the annual precipitation of a year).

Accordingly, the mean precipitation during growing season was $386.0 \mathrm{~mm}$ and the mean square error was $107.4 \mathrm{~mm}$ calculated from the precipitation data for 1971 to 2014. According to the divided method of precipitation years (Tao et al., 2000), during the growing season, the amount of precipitation in wet year is greater than $422.4 \mathrm{~mm}$, the year with precipitation less than $352.6 \mathrm{~mm}$ is considered as a dry year, and in a normal year, the precipitation is $352.6-422.4 \mathrm{~mm}$.

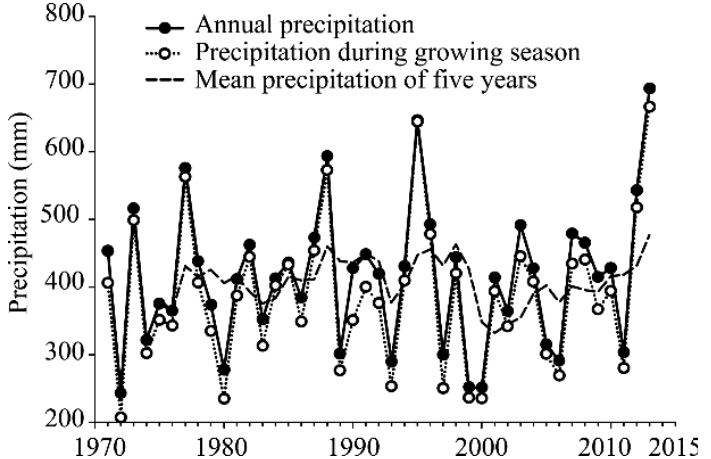

Fig. 2 Annual precipitation, precipitation during growing season and mean precipitation of five years during period of 1973-2014 at the study site

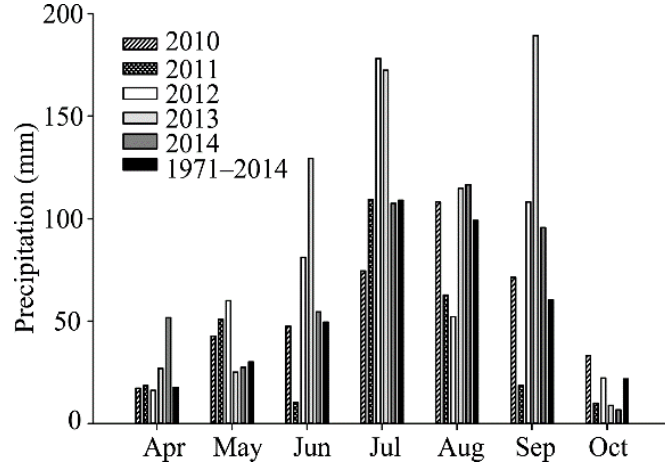

Fig. 3 The description of monthly precipitation for year of 2010-2014 and the mean annual precipitation for 1971-2014 during April to October

During the monitoring period of 2010-2014, the total precipitation amounts were 394.0, 280.0, $517.8,666.5$ and $459.8 \mathrm{~mm}$, respectively during April to October. Thus, the year of 2010 is a normal year with 1.03 times of $\overline{\mathrm{P}}, 2011$ is a dry year with 1.27 times of $\overline{\mathrm{P}}, 2012$ and 2014 are wet years with 1.34 and 1.19 times of $\bar{P}$. The precipitation during the growing season of 2013 was $666.5 \mathrm{~mm}$, which was 1.73 times of $\bar{P}$. Hence, the year of 2013 was defined as the extremely wet year. Furthermore, the distributions of monthly precipitation between 2012 and mean values of 1971 to 2014 was not consistent, especially in July; while the monthly precipitation distribution of 2012 was agree with the distribution of mean values. Thus, we chose 2014 as the classical wet year in this study.

\section{Results and discussion}

\subsection{Response of soil water to precipitation years and vegetation types}

2.1.1 The vertical distribution of soil water

The distribution of spatial mean SWS in 0-4.0 m differed notably among the four vegetation types during the growing seasons under normal (2010), dry (2011), wet (2014) and extremely wet (2013) 
years (Fig. 4). The crop site always had the highest SWS than other types in different soil layers $(0-1.0,1.0-2.0,2.0-3.0$ and 3.0-4.0 m). The fallow plot had the second high SWS, which were significantly higher than those under both shrub and pasture. This order was constant with the changes in normal, dry, wet and extremely wet year. SWS in the different layers under the two types of planted vegetations (Caragana and alfalfa) had no significant difference according to ANOVA analysis. The shrub plot had the lowest SWS in 0-1.0 and 1.0-2.0 m during the study period. However, in 2.0-3.0 m layer, SWS under pasture was lower than under shrub in 2014, and there was
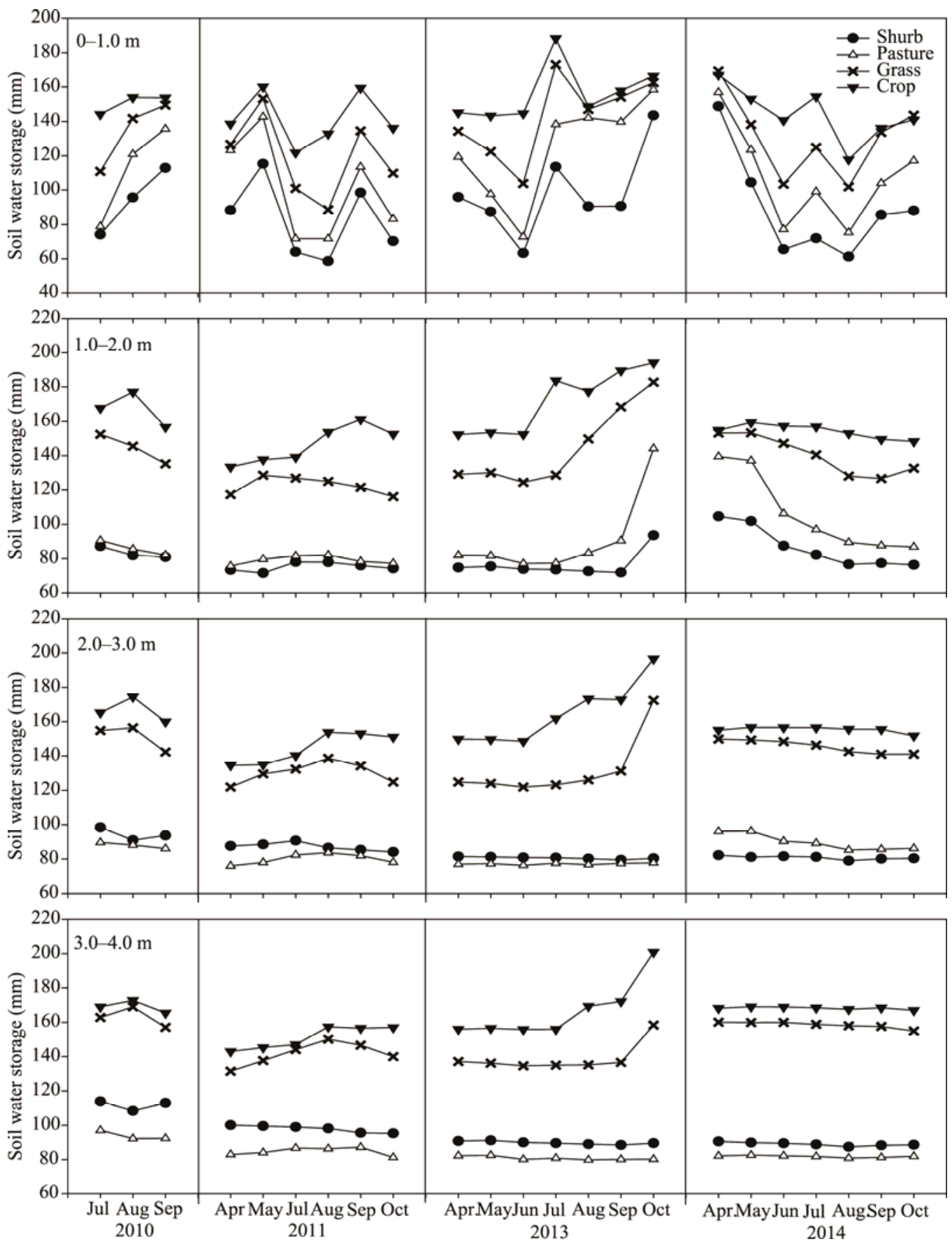

Fig. 4 Soil water storage in the soil depths of $0-1.0,1.0-2.0,2.0-3.0$ and 3.0-4.0 m under shrub, pasture, fallow and crop during the growing seasons 
the same tendency in 3.0-4.0 m layer during the study period. The observations showed that shrub and pasture had different water consumption layers, Caragana consumed more soil water than alfalfa in 0-2.0 m layer, and conversely in 2.0-4.0 m layer. This was due to the differences in the root profile distributions of the plants, the fine root density of Caragana was 1.5 times higher than that of alfalfa in the 0-2.0 m layer, while the root distribution of alfalfa was deeper than Caragana in our study area (Chen et al., 2007).

The results of mean SWC in 0-4.0 m profile for the four vegetation types were similar with the SWS changes (Fig. 5). The SWC in 0-1.0 m layers did not differ notably among the four vegetation types in the four study years, however, in 1.0-4.0 m layers, the SWCs under shrub and pasture were
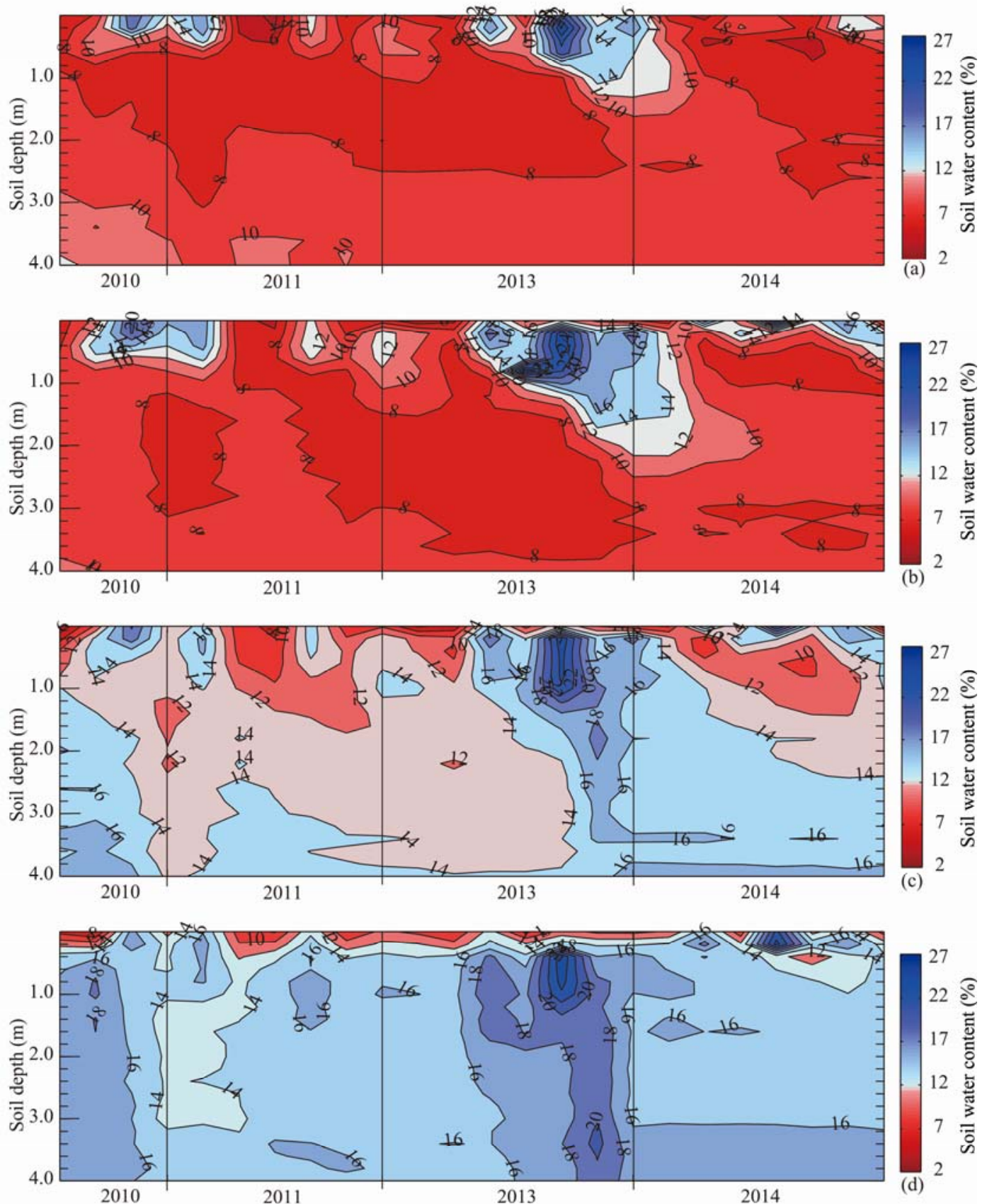

Fig. 5 Vertical distributions and temporal dynamics of soil water content (\%) in 0-4.0 m profiles under shrub (a), pasture (b), fallow (c) and crop (d) during growing seasons in different precipitation years 
notably lower than the SWCs under fallow and crop, consistently ranging mainly from $8 \%$ to $10 \%$ in 1.0-4.0 m depths (Fig. 5; Table 3). The four plots were located on a hillslope with a relatively uniform slope $\left(12-14^{\circ} \mathrm{C}\right)$ and similar soil physical properties (Table 1), thus the impact of soil physical properties and topography on the SWC can be eliminated in this study. The continuouslylower SWC under shrub and pasture than that under fallow and crop in $0-4.0 \mathrm{~m}$ profile was mainly due to the difference of vegetation species. The results showed that planted vegetation in the shrub and pasture plots consumed more soil water than either the native species in the follow or the crop plots.

Table 3 Satistical values of mean soil water contents in the profiles during the study period

\begin{tabular}{|c|c|c|c|c|c|c|c|c|c|}
\hline \multirow[b]{2}{*}{ Plot } & \multirow[b]{2}{*}{ Year } & \multicolumn{2}{|c|}{$0-1.0 \mathrm{~m}$} & \multicolumn{2}{|c|}{$1.0-2.0 \mathrm{~m}$} & \multicolumn{2}{|c|}{$2.0-3.0 \mathrm{~m}$} & \multicolumn{2}{|c|}{$3.0-4.0 \mathrm{~m}$} \\
\hline & & $\begin{array}{c}\text { Mean } \\
(\%)\end{array}$ & $\begin{array}{l}\text { CV } \\
(\%)\end{array}$ & $\begin{array}{c}\text { Mean } \\
(\%)\end{array}$ & $\begin{array}{l}\text { CV } \\
(\%)\end{array}$ & $\begin{array}{l}\text { Mean } \\
(\%)\end{array}$ & $\begin{array}{l}\text { CV } \\
(\%)\end{array}$ & $\begin{array}{c}\text { Mean } \\
(\%)\end{array}$ & $\begin{array}{l}\mathrm{CV} \\
(\%)\end{array}$ \\
\hline \multirow{5}{*}{$\begin{array}{c}\text { Shrub } \\
\text { (Caragana) }\end{array}$} & 2010 & $9.42^{\mathrm{a}}$ & 20.61 & $8.34^{\mathrm{ab}}$ & 4.01 & $9.44^{\mathrm{a}}$ & 3.99 & $11.18^{\mathrm{a}}$ & 2.63 \\
\hline & 2011 & $8.18^{\mathrm{a}}$ & 24.70 & $7.53^{\mathrm{a}}$ & 3.14 & $8.40^{\mathrm{b}}$ & 8.51 & $9.61^{\mathrm{b}}$ & 3.64 \\
\hline & 2013 & $10.89^{\mathrm{a}}$ & 33.95 & $7.65^{\mathrm{a}}$ & 8.79 & $8.07^{b}$ & 0.89 & $8.97^{\mathrm{c}}$ & 1.10 \\
\hline & 2014 & $9.00^{\mathrm{a}}$ & 29.43 & $8.64^{\mathrm{b}}$ & 13.55 & $8.08^{b}$ & 1.24 & $8.90^{c}$ & 1.14 \\
\hline & 2010 & $11.18^{\mathrm{a}}$ & 26.35 & $8.61^{\mathrm{a}}$ & 5.01 & $8.80^{\mathrm{a}}$ & 3.03 & $9.39^{\mathrm{a}}$ & 2.92 \\
\hline \multirow{3}{*}{$\begin{array}{l}\text { Pasture } \\
\text { (Alfalfa) }\end{array}$} & 2011 & $9.82^{\mathrm{a}}$ & 28.72 & $7.91^{\mathrm{a}}$ & 2.87 & $8.00^{\mathrm{b}}$ & 3.50 & $8.47^{\mathrm{b}}$ & 2.60 \\
\hline & 2013 & $13.58^{a}$ & 32.81 & $9.09^{\mathrm{ab}}$ & 25.52 & $7.73^{b c}$ & 0.65 & $8.11^{\mathrm{c}}$ & 1.24 \\
\hline & 2014 & $10.78^{a}$ & 25.62 & $10.58^{b}$ & 20.25 & $8.97^{\mathrm{a}}$ & 5.00 & $8.18^{c}$ & 0.69 \\
\hline \multirow{4}{*}{$\begin{array}{c}\text { Fallow } \\
\text { (Natural } \\
\text { grass) }\end{array}$} & 2010 & $13.40^{\mathrm{a}}$ & 15.21 & $14.44^{\mathrm{a}}$ & 5.98 & $15.12^{\mathrm{a}}$ & 5.11 & $16.29^{\mathrm{a}}$ & 3.67 \\
\hline & 2011 & $11.91^{\mathrm{a}}$ & 18.17 & $12.34^{\mathrm{a}}$ & 6.00 & $13.09^{b}$ & 5.94 & $14.21^{\mathrm{b}}$ & 5.93 \\
\hline & 2013 & $15.35^{\mathrm{b}}$ & 24.54 & $14.50^{\mathrm{b}}$ & 16.37 & $13.18^{b}$ & 12.95 & $13.83^{\mathrm{bc}}$ & 4.69 \\
\hline & 2014 & $13.03^{\mathrm{ac}}$ & 15.61 & $13.98^{\mathrm{ab}}$ & 8.06 & $14.56^{\mathrm{ac}}$ & 2.56 & $15.84^{\mathrm{ad}}$ & 0.99 \\
\hline \multirow{4}{*}{$\begin{array}{c}\text { Crop } \\
\text { (Soybean } \\
\text { or millet) }\end{array}$} & 2010 & $15.06^{\mathrm{a}}$ & 7.87 & $16.71^{\mathrm{a}}$ & 6.14 & $16.65^{\mathrm{a}}$ & 4.42 & $16.79^{\mathrm{a}}$ & 3.34 \\
\hline & 2011 & $14.15^{\mathrm{a}}$ & 9.88 & $14.67^{\mathrm{b}}$ & 6.89 & $14.48^{b}$ & 5.70 & $14.81^{\mathrm{b}}$ & 3.35 \\
\hline & 2013 & $16.64^{\mathrm{b}}$ & 17.49 & $17.36^{\mathrm{ac}}$ & 11.75 & $16.58^{\mathrm{ac}}$ & 10.89 & $16.36^{\mathrm{ac}}$ & 7.57 \\
\hline & 2014 & $14.50^{\mathrm{ac}}$ & 9.47 & $15.43^{\mathrm{ab}}$ & 2.46 & $15.55^{\mathrm{ab}}$ & 0.92 & $16.99^{\mathrm{ac}}$ & 0.60 \\
\hline
\end{tabular}

Note: The values of CV refer to the coefficient of variation which were computed in the time series of the mean soil water content in 0 $4.0 \mathrm{~m}$ profiles. The same letter indicates no significant difference and the different letters of a, b, c, d indicate there are significant differences of soil water content among different years at $P<0.05$ level.

\subsubsection{Soil water dynamics}

Figures 4 and 5 showed the dynamics of soil water vertical distribution in the $0-4.0 \mathrm{~m}$ soil profile during the growing season in 2010,2011, 2013 and 2014. The temporal variations in soil water differed for the four vegetation types and followed a similar change-pattern with precipitation changes for all vegetation types over the four years. Under fallow and crop, rainwater infiltration and percolation affected the SWC in the deep soil layers, especially in extremely wet year. In the normal and dry year, the greatest variations in soil water tend to occur in the $0-1.0 \mathrm{~m}$ soil layer, while decreased slightly below $1.0 \mathrm{~m}$ soil depth under the four vegetation types. In extremely wet year, the dynamic changes in soil water occurred in the 0-2.0 m layer under shrub and pasture, however, approximately extended to the depth of $4.0 \mathrm{~m}$ under fallow and crop. In the wet year, soil water decreased in 0-2.0 m for Caragana and alfalfa, while the depth of soil water dynamics was 0-1.0 $\mathrm{m}$ for fallow and crop, which mainly due to the deeper root distribution of Caragana and alfalfa. The results indicated that precipitation and vegetation types jointly influenced temporal dynamics of soil water in the study region. Salve et al. (2011) also reported that both precipitation and vegetation had a notable interactive effect on soil water dynamics, and precipitation was the most significant factor determining soil water dynamics. Land use/cover could give rise to differences in evapotranspiration that also affect soil water level, and different vertical distributions of soil water of four vegetation types implied a potential infiltration (Fu et al., 2003; Sun et al., 2006; Oudin et al., 2008). The coefficient of temporal variation (CV) of SWC decreased with soil depth under the four vegetation types, indicating that the temporal variations of mean SWC decreased with soil depth and mainly occurred in shallow layers (Table 3). In this study, it was clear that vegetation type affected the consumption of soil water at the deeper soil layers, while precipitation mainly influenced the temporal dynamics of soil water through the rainwater replenishment in shallow layers.

The inter-annual fluctuations of soil water in $0-4.0 \mathrm{~m}$ profiles greatly occurred in the shallow 
layer within certain depths, and Wang et al. (2009a) reported the analogous observation. In different precipitation years, the soil depths of SWC variations can be observed as deep as to 1.6, 2.2 and $3.4 \mathrm{~m}$ for shrub, pasture and fallow while it was further down to $4.0 \mathrm{~m}$ under crops (Fig. 6). SWCs in these converging depths showed the pattern of extremely wet year $>$ wet year $>$ normal year $>$ dry year, while there was very small difference in soil water for the four years below these depths with the highest SWCs in normal year under shrub and pasture. This may be caused by increasing evapotranspiration of alfalfa and Caragana with plants growth, which depleting soil water stored in deep soil with deep-rooted distribution (Wang et al., 2009b, 2012). The SWCs in 0-4.0 m under fallow and crop were both showed lowest in dry year (2011) and highest in extremely wet year (2013). These results demonstrated the inter-annual variations of soil water mainly resulted by the difference of annual precipitation, which was agree with the report by Wang et al. (2009a). In dry year, the precipitation mainly occurred in July and August, SWCs in four vegetation plots were all decreased during the growing season, because of low precipitation in dry year cannot satisfy water consumption which resulted in the soil water depletion in deep soil layers. In the extremely wet year, there was an overall increase in SWC under the four vegetation types due to high amounts of consecutive monthly rainfall, which suggested that soil water was in surplus due to the recharge of

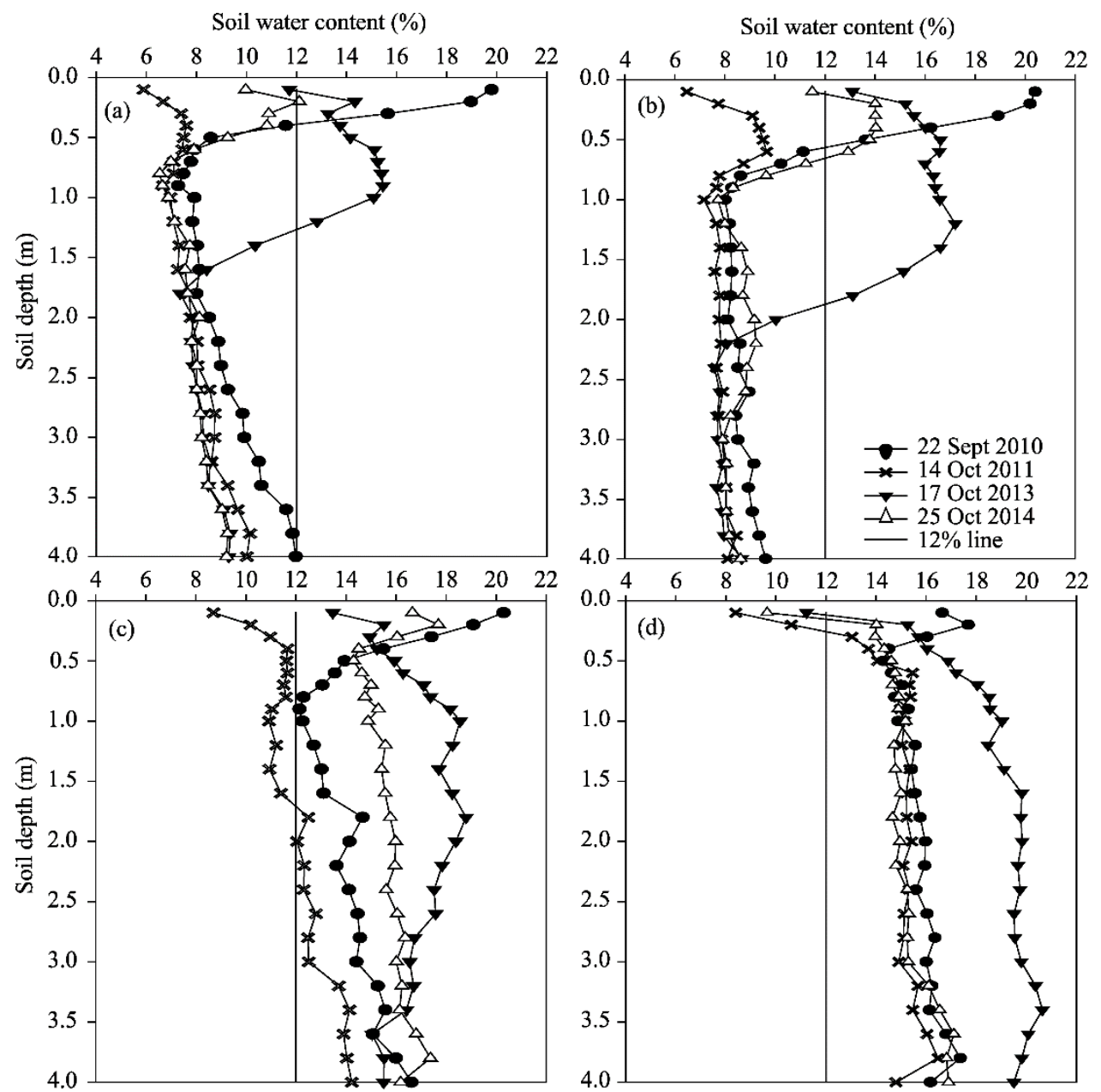

Fig. 6 Vertical distributions of soil water contents in 0-4.0 m profiles under (a) shrub, (b) pasture, (c) fallow and (d) crop at the end of the measured period of the four precipitation years. $12 \%$ line, stable water content line.

soil water by consecutive heavy rains for all vegetation types during the study period. The results inferred annual precipitation pattern and vegetation type jointly control soil water dynamics in space and time and affect rainfall infiltration, agreed with the study by Van den Elsen (2003). 


\subsection{Replenishment of soil water under different precipitation years}

Rainwater that infiltrates the soil and percolates to depth is the only water source of available soil water needed to meet evapotranspiration and to sustain vegetation growth on the Loess Plateau. This is because, the groundwater is generally much deeper $(>60 \mathrm{~m})$ than the rooting depth capacity of most plants and is thus not directly available to them; neither can it rise to the soil surface by capillary flow. By measuring the SWCs at different time point, we knew that once the rainfall replenishment reached the maximum depth, soil water content at the layers deeper than the maximum replenishment depth would undergo a relatively constant period during a year (Yang and $\mathrm{Yu}, 1992)$. Thus, the depth at which SWC vertical distribution under measured periods converged could be taken as rainfall recharge depth. Infiltration depths varied among the four precipitation years for each vegetation type (Fig. 5). In normal year, the replenished depths were about 1.0, 1.0, 1.2 and $1.2 \mathrm{~m}$, respectively under the shrub, pasture, fallow and crop. In dry year, the largest replenished depths were about $0.6,1.0,1.4$ and $1.6 \mathrm{~m}$, and in the wet year (2014), the depths were $0.7,0.9,1.6$ and $1.8 \mathrm{~m}$, respectively under the shrub, pasture, fallow and crop. In extremely wet year, the depths were the largest for all the four vegetation types, which were at 1.6, 2.2, $3.4 \mathrm{~m}$ and surpass $4.0 \mathrm{~m}$, respectively (Fig. 5). At the end of the monitoring period in 2013, SWCs in 0-4.0 m profile mainly ranged from $14 \%$ to $24 \%$ under fallow, and SWCs in $0-4.0 \mathrm{~m}$ profile were almost at the level of field capacity under crop ranging from $18 \%$ to $24 \%$. The results showed that precipitation could replenish soil water in deeper soil layers under crop and fallow than under shrub and pasture in different precipitation years. The different amounts and vertical distributions of SWC under the four vegetation types could imply a potential variability in soil infiltration capability $(\mathrm{Fu}$ et al., 2003). The larger water demand for transpiration in Caragana and alfalfa not only desiccated the deep soil layers, but also confined rainwater percolation to within the shallower soil layers while restricting percolation of rainwater to deeper layers. These further confirmed that, as mentioned above, the annual precipitation pattern and vegetation type jointly controlled soil water dynamics in both space and time, and affected rainwater infiltration, as also reported by Van den Elsen (2003) in a study carried on the Loess Plateau.

In normal, dry and wet years, rainfall mainly recharged the $0-1.0 \mathrm{~m}$ soil layer for shrub and pasture. Although there were consecutive wet years (2012, 2013, 2014), and experienced an extremely wet year, the rainfall replenishment depth under shrub and pasture was still limited into $2.0 \mathrm{~m}$. The shallower recharge depths for the two perennials indicated that the rainwater infiltration was mainly stored in shallow layers and was directly consumed by evapotranspiration. However, the replenished depth under crop was actually deeper than the measured depth of $4.0 \mathrm{~m}$. Previous studies have also demonstrated that rainfall infiltration depth was beyond $3.0 \mathrm{~m}$ for cropland or natural grassland but always less than $2.0 \mathrm{~m}$ for shrubs, grass and forests in other areas of the Loess Plateau (Zhang et al., 2004; Huo and Shao, 2005; Xu et al., 2005; Wang et al., 2009a). The results indicated that exotic vegetation could inhibit rainwater recharge to deep soil layers due to higher levels of soil water consumption and low SWC, as also reported by Oudin et al. (2008) and Fu et al. (2012). Caragana and alfalfa, with larger and deeper roots than crops do and very high levels of transpiration, generally consume much more water from deeper soil layers, even desiccate deep soil layers. Therefore, the low SWC induced by Caragana and alfalfa in the upper soil layers tend to confine rainwater recharge to those layers, thereby restricting the recharge of the deeper layers (Wang et al., 2010). It is necessary to plant perennial vegetation and annual crops or natural fallow within a mosaic pattern to maintain sustainably utilization of soil water and development of vegetation restoration.

\subsection{The characteristics of soil water depletion}

Dried soil layers with low levels of SWC, generally occurred at a certain soil depth deeper than 1.0 $\mathrm{m}$ on the Loess Plateau and may adversely affect plant survival (Huang et al., 2006; Wang et al., 2010). In our study, the stable water content (12.0\%) was the upper limit SWC of a dried soil layer, which was equal to $60 \%$ of the field capacity $(20.0 \%$; Fu et al., 2012). The depths of dried layers under shrub and pasture were differed among the four precipitation years (Fig. 5). The beginning depth of soil desiccation was consider as the largest infiltration depth in our study, soil water below 
the depth was difficult to recharge by rainfall. Thus, under shrub and pasture, soil desiccation mainly occurred in 1.0 to $4.0 \mathrm{~m}$ depths in normal year, with SWCs decreased over time mainly ranging from $8 \%$ to $12 \%$ and $8 \%$ to $10 \%$, respectively. In dry year, fewer precipitation aggravated soil desiccation in $0.6-4.0$ and $1.0-4.0 \mathrm{~m}$ depths under shrub and pasture, respectively. The depths of dried soil layer under shrub and pasture were from $0.7-4.0$ and $0.9-4.0 \mathrm{~m}$ in wet year, and 1.64.0 and 2.0-4.0 $\mathrm{m}$ in extremely wet year, respectively. Fu et al. (2003) also reported that dried soil layers appeared at depths of 1.0-2.6 m under shrub and 1.0-3.6 m under pasture, using the soil water data in 2009 for the same plots.

The depths of the dried layers likely exceeded $4.0 \mathrm{~m}$ under shrub and pasture, while no dried layers formed below $1.0 \mathrm{~m}$ under fallow and crop under the four study years (Fig. 5). These results were consistent with those of previous studies, which reported that re-vegetation aggravated water scarcity and gradually resulted in dried soil layers forming in deep soil layer (Wang et al., 2011; Fu et al., 2012; Jia and Shao, 2014). This was because the evapotranspiration of the planted perennials always exceeded the amount of precipitation on the Loess Plateau, which prevents soil water replenishment (Huang et al., 2006; Jia and Shao, 2014). Planting high water-consumption exotic shrub and grass species in the study area depletes soil water and creates dried soil layers due to their great ability to extract water and, when the soil has been desiccated to such a degree, then their survival is solely dependent on the precipitation. In conclusion, natural restoration should be the preferred method and that restoration using artificial species should be limited during vegetation restoration projects, this conclusion is in agreement with the suggestions of other studies (Wen et al., 2005; Zhang and Liu, 2008). However, such artificial species could be planted as an intermediary step in order to rapidly establish cover and prevent soil erosion before converting them incrementally to natural grassland. The infiltrated rainwater mostly stayed in the $0-1.0 \mathrm{~m}$ soil layer and hardly supplied to soil below a depth of $1.0 \mathrm{~m}$ in normal, dry and wet rainfall years. Between 1971 and 2013, precipitation exceeded $600 \mathrm{~mm}$ only in 1995 and 2013, so rainwater percolation probably did not exceed $2.0 \mathrm{~m}$ under shrub and pasture during this period when the annual precipitation was relatively low. Wang et al. (2010) and Fu et al. (2012) carried out studies on our study area also suggested that the rainwater recharge depth was about $1.0 \mathrm{~m}$ under Caragana and alfalfa. This implied that soil desiccation was difficult to remove under shrub and pasture with the input of annual infiltrated rainwater in normal, dry and wet years, and soil desiccation removed only in 1.0-2.0 m layer even in the year of 2013. Thus, it is essential to select proper plant types based on rainfall and soil water conditions for effectively minimizing negative effects of soil desiccation. In order to sustainably utilize soil water and to improve ecological environment, one suggestion is that artificial vegetation types should be planted among areas with native grasses or crops in mosaic patterns. Fu et al. (2012) also proposed planting shrubs or grasses on the lower ends of slopes, while natural regeneration should be encouraged on the upper parts in order to maintain the sustainable development of vegetation restoration.

\section{Conclusions}

This study investigated temporal dynamics and profile characteristics of soil water in $0-4.0 \mathrm{~m}$ soil profiles on a hillslope under different precipitation years, in relation to four vegetation types: shrub, pasture, fallow and crop on the northern Loess Plateau of China. The precipitation years and vegetation types jointly controlled the temporal dynamics and profile characteristics of soil water in the study region. Precipitation influenced the temporal dynamics of soil water through the rainwater replenishment in shallow layers, while vegetation type mainly affected the variations of soil water in deep soil layer.

SWCs and SWSs in $0-4.0 \mathrm{~m}$ soil profiles followed the sequence of crop $>$ fallow $>$ shrub $>$ pasture under the four precipitation years. The temporal variations of soil water varied among years dependent on annual precipitation for each vegetation type. In extremely wet year, the dynamic changes of soil water occurred in the $0-2.0 \mathrm{~m}$ layer under shrub and pasture, however, approximately extended to the depth of $4.0 \mathrm{~m}$ under fallow and crop. In other three precipitation years, soil water mainly changed in the $0-1.0 \mathrm{~m}$ layer, while below $1.0 \mathrm{~m}$ depth decreased slightly 
under the four vegetation types. SWCs in these depths showed extremely wet year>wet year>normal year $>$ dry year, while below these depths, soil water changed slightly in the four years for each type of vegetation.

Compared to crop plot, the depth of soil water depletion in shrub and pasture plots all exceeded $4.0 \mathrm{~m}$, and dried soil layers continued to existed below $2.0 \mathrm{~m}$ in extreme precipitation year. However, no dried soil layers existed under fallow and crop under the four precipitation years. Artificial vegetation could weaken the rainfall replenishment to deep soil due to increasing evapotranspiration and low profile soil water.

The infiltrated rainwater mostly stayed in the $0-1.0 \mathrm{~m}$ soil layer, implied that soil desiccation was difficult to remove under shrub and pasture with the input of annual infiltrated rainwater in normal, dry and wet years, and soil desiccation removed only in 1.0-2.0 m layer even in the extremely wet year of 2013. The observations of this study also indicated that fallow was the best vegetation type for maintaining a sustainable water balance. The results provided some valuable information for land use planning and could be applied to attain long-term sustainability of vegetation restoration projects and to utilize soil water resources rationally. However, an overall land-use management plan might involve the use of artificial vegetation types, native fallow and crops planted in areas that form a mosaic pattern for economic reasons.

\section{Acknowledgments}

The study was financially supported by the National Natural Science Foundation of China (51179180, 41390463). The State Key Laboratory of Soil Erosion and Dryland Farming on the Loess Plateau is appreciated. We also acknowledge the help from Dr. JIA Yuhua in data collection.

\section{References}

Chen H S, Shao M A, Li Y Y. 2008a. Soil desiccation in the Loess Plateau of China. Geoderma, 143(1-2): 91-100.

Chen H S, Shao M A, Li Y Y. 2008b. The characteristics of soil water cycle and water balance on steep grassland under natural and simulated rainfall conditions in the Loess Plateau of China. Journal of Hydrology, 360(1-4): $242-251$.

Chen L D, Huang Z L, Gong J, et al. 2007. The effect of land cover/vegetation on soil water dynamic in the hilly area of the Loess Plateau, China. Catena, 70(2): 200-208.

Chen L D, Wang J P, Wei W, et al. 2010. Effects of landscape restoration on soil water storage and water use in the Loess Plateau Region, China. Forest Ecology and Management, 259(7): 1291-1298.

D'Odorico P, Caylor K, Okin G S, et al. 2007. On soil moisture-vegetation feedbacks and their possible effects on the dynamics of dryland ecosystems. Journal of Geophysical Research: Biogeosciences (2005-2012), 112(G4): G04010.

Farley K A, Jobbágy E G, Jackson R B. 2005. Effects of afforestation on water yield: a global synthesis with implications for policy. Global Change Biology, 11(10): 1565-1576.

Fu B J, Wang J, Chen L D, et al. 2003. The effects of land use on soil moisture variation in the Danangou Catchment, the Loess Plateau of China. Catena, 54(1-2): 197-213.

Fu X L, Shao M A, Wei X R, et al. 2012. Effects of monovegetation restoration types on soil water distribution and balance on a hillslope in northern Loess Plateau of China. Journal of Hydrologic Engineering, 18(4): 413-421.

Gish T J, Prueger J H, Daughtry C S T, et al. 2011. Comparison of field-scale herbicide runoff and volatilization losses: an eightyear field investigation. Journal of Environmental Quality, 40(5): 1432-1442.

Huang Y L, Chen L D, Fu B J, et al. 2006. Experimental study on ecological water use in a gully catchment of the Loess Plateau: effects of climate and land-use change. Advances in Water Science, 17(1): 14-19. (in Chinese)

Huo Z, Shao M A. 2005. Soil water distribution of the shrub land at the gully bank in the wind-water erosion crisscross region of Loess Plateau in China. Transactions of CSAE, 21(6): 45-49. (in Chinese)

Huo Z, Shao M A, Horton R. 2008. Impact of gully on soil moisture of shrubland in wind-water erosion crisscross region of the Loess Plateau. Pedosphere, 18(5): 674-680.

Ingmar M, Chen L D, Rudi H. 2003. Soil conditions in a small catchment on the Loess Plateau in China. Catena, 54(1-2): 45-58.

Jia Y H, Shao M A. 2014. Dynamics of deep soil moisture in response to vegetational restoration on the Loess Plateau of China. Journal of Hydrology, 519: 523-531.

Kerkhoff A J, Martens S N, Shore G A, et al. 2004. Contingent effects of water balance variation on tree cover density in semiarid woodlands. Global Ecology and Biogeography, 13(3): 237-246.

Legates D R, Mahmood R, Levia D F, et al. 2011. Soil moisture: a central and unifying theme in physical geography. Progress in Physical Geography, 35(1): 65-86. 
Li X Y. 2011. Mechanism of coupling, response and adaptation between soil, vegetation and hydrology in arid and semiarid regions. Scientia Sinica Terrae, 41(12): 1721-1730. (in Chinese)

Li X Y, Zhang S Y, Peng H Y, et al. 2013. Soil water and temperature dynamics in shrub-encroached grasslands and climatic implications: results from Inner Mongolia steppe ecosystem of north China. Agricultural and Forest Meteorology, 171-172: 20-30.

Messing I, Chen L D, Hessel R. 2003. Soil conditions in a small catchment on the Loess Plateau in China. Catena, 54(1-2): 45-58.

Mohammad A G, Adam M A. 2010. The impact of vegetative cover type on runoff and soil erosion under different land uses. Catena, 81(2): 97-103.

Nosetto M D, Jobbágy E G, Tóth T, et al. 2007. The effects of tree establishment on water and salt dynamics in naturally saltaffected grasslands. Oecologia, 152(4): 695-705.

Oudin L, Andréassian V, Lerat J, et al. 2008. Has land cover a significant impact on mean annual streamflow? An international assessment using 1508 catchments. Journal of Hydrology, 357(3-4): 303-316.

Porporato A, D’Odorico P, Laio F, et al. 2002. Ecohydrology of water-controlled ecosystems. Advances in Water Resources, 25(8-12): 1335-1348.

Reszkowska A, Krümmelbein J, Peth S, et al. 2011 Influence of grazing on hydraulic and mechanical properties of semiarid steppe soils under different vegetation type in Inner Mongolia, China. Plant and Soil, 340(1-2): 59-72.

Salve R, Sudderth E A, Clair S B S, et al. 2011. Effect of grassland vegetation type on the responses of hydrological processes to seasonal precipitation patterns. Journal of Hydrology, 410(1-2): 51-61.

Shangguan Z P. 2007. Soil desiccation occurrence and its impact on forest vegetation in the Loess Plateau of China. International Journal of Sustainable Development and World Ecology, 14(3): 299-306.

Sun G, Zhou G Y, Zhang A Q, et al. 2006. Potential water yield reduction due to forestation across China. Journal of Hydrology, 328(3-4): 548-558.

Tao L W, Ma H, Ge F L. 2000. Analysis on the characteristics of precipitation in Shannxi Province. Shaanxi Meteorology, (5): 6-9. (in Chinese)

Van den Elsen E, Hessel R, Liu B Y, et al. 2003. Discharge and sediment measurements at the outlet of a watershed on the Loess plateau of China. Catena, 54(1-2): 147-160.

Wang L, Wang Q J, Wei S P, et al. 2008. Soil desiccation for Loess soils on natural and regrown areas. Forest Ecology and Management, 255(7): 2467-2477.

Wang M B, Li H J, Chai B F. 1996. Effect of extreme rainfall on the soil water cycle of forest land. Journal of Soil Erosion and Soil and Water Conservation, 2(3): 83-87, 92. (in Chinese)

Wang S, Fu B J, He C S, et al. 2011. A comparative analysis of forest cover and catchment water yield relationships in northern China. Forest Ecology and Management, 262(7): 1189-1198.

Wang Y Q, Shao M A, Shao H B. 2010. A preliminary investigation of the dynamic characteristics of dried soil layers on the Loess Plateau of China. Journal of Hydrology, 381(1-2): 9-17.

Wang Y Q, Shao M A, Liu Z P, et al. 2012. Regional spatial pattern of deep soil water content and its influencing factors. Hydrological Sciences Journal, 57(2): 265-281.

Wang Y Q, Shao M A, Liu Z P. 2013. Vertical distribution and influencing factors of soil water content within 21-m profile on the Chinese Loess Plateau. Geoderma, 193-194: 300-310.

Wang Z Q, Liu B Y, Zhang Y. 2009a. Soil moisture of different vegetation types on the Loess Plateau. Journal of Geographical Sciences, 19(6): 707-718.

Wang Z Q, Liu B Y, Liu G, et al. 2009b. Soil water depletion depth by planted vegetation on the Loess Plateau. Science in China Series D: Earth Sciences, 52(6): 835-842.

Wen Z M, Jiao F, Pu Y J, et al. 2005. Natural restoration of vegetation and dynamic changes of species diversity in gully regions on Loess Plateau-case study in Wuqi County. Research of Soil and Water Conservation, 12(1): 1-3. (in Chinese)

Wilson D J, Western A W, Grayson R B. 2004. Identifying and quantifying sources of variability in temporal and spatial soil moisture observations. Water Resources Research, 40(2) W02507, doi: 10.1029/2003WR002306.

Xu X X, Zhang B Y, Ju T J. 2005. The spatial-temporal distribution of rainfall, runoff, and soil water in small watershed and its utilization. Ecology and Environment, 14(6): 890-893. (in Chinese)

Yang W Z, Yu C Z. 1992. Regional Management and Evaluation of Loess Plateau. Beijing: Science Press, 241-297. (in Chinese)

Yao S X, Zhao C C, Zhang T H, et al. 2013. Response of the soil water content of mobile dunes to precipitation patterns in Inner Mongolia, northern China. Journal of Arid Environments, 97: 92-98.

Zeng C, Shao M A, Wang Q J, et al. 2011. Effects of land-use on temporal-spatial variability of soil water and soil-water conservation. Acta Agriculturae Scandinavica, Section B-Soil and Plant Science, 61(1): 1-13.

Zhang C X, Hao M D, Wei X R, et al. 2004. Soil water distribution characteristics of alfalfa with different planting years in the gully region of loess plateau. Plant Nutrition and Fertilizer Science, 10(6): 604-607. (in Chinese)

Zhang W H, Liu G B. 2008. Review and proposals on vegetation restoration in the Loess Plateau, Northwest China. Frontiers of Forestry in China, 3(1): 85-91. 